\title{
DIFFERENTIAL PAIRING AND MATING IN THE PRIMITIVE INSECT CYPHODERRIS STREPITANS (ORTHOPTERA:HAGLIDAE)
}

\author{
Glenn K. Morris \\ Department of Zoology and Erindale College \\ University of Toronto \\ Toronto, Ontario \\ Canada
}

\section{Objectives}

Cyphoderris strepitans is a cricket-like insect found in Grand Teton National Park. Males perch in sagebrush and produce a calling song which draws sexually receptive females. Singing activity is nocturnal and begins in late May and early June. Because females typically consume a part of the male's hind wings during mating (Morris 1979, Dodson et al. 1983) it is possible to follow in the field, the pairing opportunities of free-living males. In addition to sperm and the substance of their wings, males give the female a spermatophylax, and proteinaceous food gift which she eats (Gwynne 1983). To maximize such nutritional investments females should have been selected to pair with mature unmated males rather than with once-mated males; virgin males will be more capable than non-virgin (on average) of providing a maximally large and nutritious food gift (wing + spermatophylax). The objective of this research was to test the theoretical prediction that unmated males experience greater success than non-virgin males in securing a mate.

\section{Methods}

By capture, release and recapture, a study group of individually marked males was monitored for hind wing feeding damage. A field site was chosen in Grand Teton National Park near Deadman's Bar on the east side of the Snake River. Within a sagebrush habitat on the river's flood plain, a rectangular plot of 500 square meters was staked. Three workers began at dusk to stalk singing males by their sounds. They used headlamps, transferring the captured insects into numbered vials. Each singer's perch was marked with a surveyor's flagged stake, labelled with his vial number. An attempt was made over 3-4 hr to capture all singers from a large area centered on the plot, beginning in the plot itself and working increasingly to the periphery.

Brought to the research center, the Cyphoderris males were processed between $2 \mathrm{am}$ and dawn. Each male was weighed and his median pronotal length measured. The state of his hind wings was recorded photographically. Each male was marked uniquely with dots of colored enamel paint. The males were then returned to the field site and released into the ground litter below the appropriate flagged stake. All males were returned by a few hours after dawn. A final procedure involved mapping the locations of the flagged stakes. Metal 
tape rules were used to fix the distance between each capture location and two of the most convenient plot corner stakes. The above procedures were first carcied out the night of June 9, 1982; subsequently they were repeated June 12, 14 and 17.

$\underline{\text { Results }}$

The wing state of the marked and recovered males is summarized in Table 1. On the night of June 9 we marked and released 74 males: 41 were intact-winged (virgin) males; 33 had wounded wings. On June 12 we recaptured 50 of these. Twenty-one of these 50 males had intact wings and so were known not to have mated in the interval; 29 had wounded wings. Of the 29 with wounded wings, 18 were revealed by the photographs to have the same wound pattern as on June 9; 11 insects had changed. Of these altered 11, 9 were virgin when previously collected. Two were June 9 wounded males with further wing wounding.

On the night of June 12 we marked another 32 males for a total of 106 marked animals. On June 14 we recaptured 52 marked males. Of these, 19 had intact wings; 33 had wounded wings. Of the 33 with wounded wings, 28 exhibited no change in wounding pattern from June 12; 5 insects had changed. All 5 were virgin on their im mediately previous capture.

On the night of June 14 we marked another 27 males for a total of 133 marked insects. On June 17 we recaptured 57 marked males. Of these, 16 had intact wings; 41 had wounded wings. Of the 41 wounded-wing males, 34 exhibited no change in wounding pattern from June 14; 7 insects had changed. Five of the changed males were previously taken as virgins, 2 as wounded. Considering only the five non-collection nights between June 9 and 17, only $9 \%$ of the marked insects were wounded per night.

Males of both classes (intact and wounded) invest singing nights in the acquisition of mates. To test a null hypothesis of no difference in mate acquisition between these classes we estimated the proportion of intact to wounded males over the seven-day study interval and used this to determine an expected wounding incidence. By expressing our variable in 'singer nights' we obtained an estimate which reflected more closely, fluctuations in the intact:wounded proportion during the course of the 7-day study.

On June 9 we collected 74 males of which 41 were intact, 33 wounded. On this basis we estimate, as singing activity begins on the night of June 10, an intact: wounded proportion of $41: 33$ (1.2:1). During the 10th and 11th, nights of non-collection, this proportion should shift in the direction of fewer intact males (assuming recruitment of maturing males is not appreciable). Thus 1.2:1 is probably an overestimate of the relative number of intact males during June 10 and 11. The expected pairing success under the null will therefore overestimate the numbers of encounters that should accrue to virgin males. If the number of virgin pairings actually observed is still significantly more than this overestimate would lead us to expect, we have increased confidence in concluding that intact-wing males enjoy a significant pairing advantage over wounded males. 


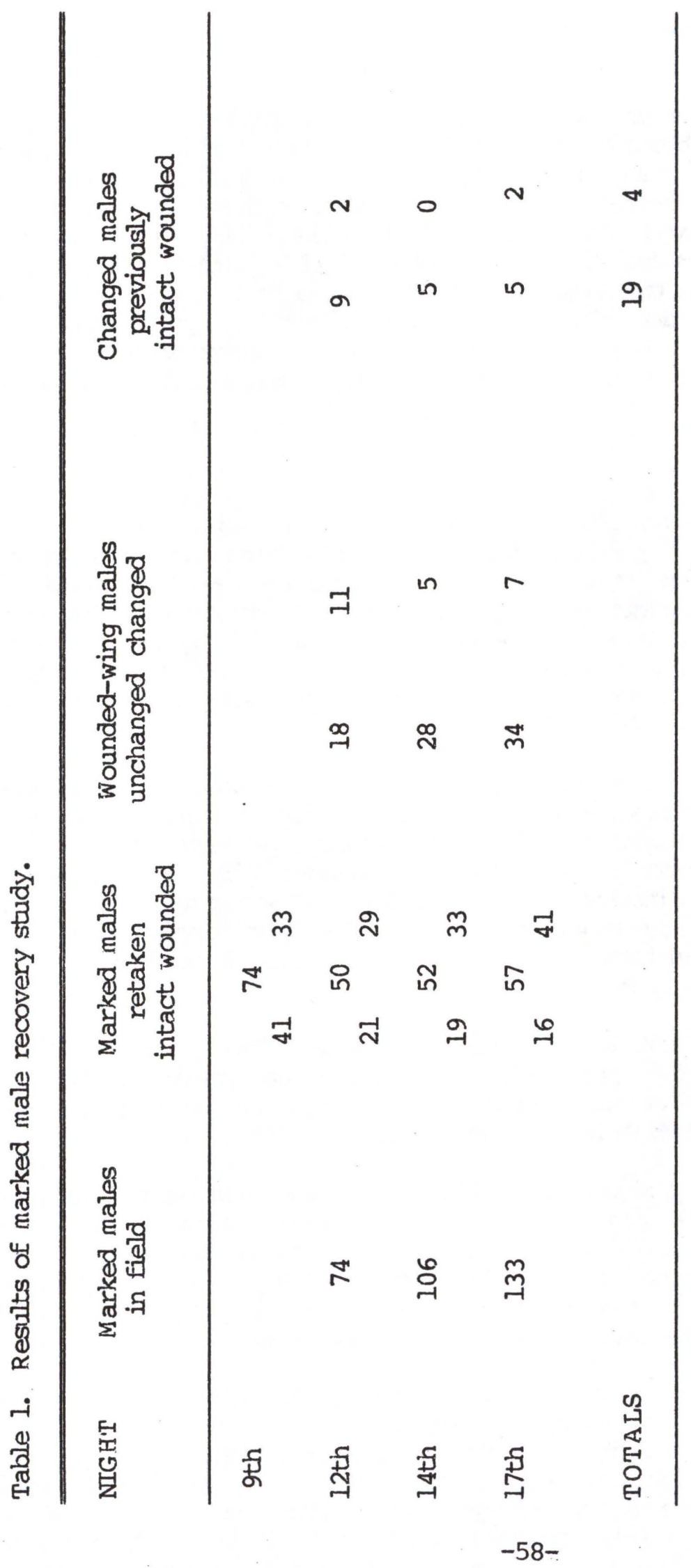


In estimating the proportion of singer nights (Table 2) invested by the two male types we have therefore used the relative number of insects of each kind taken on the previous collection night. Over the 7-day study interval if intact males paired in accordance with their relative investment in singing nights, 10.8 of the 23 observed woundings should have been to intact-wing males. Wounded-wing males should have obtained 12.2 pairings. The observed result of 19 woundings to previously intact males vs only 4 to previously wounded males, leads to a rejection of the null at the $1 \%$ level of significance (Chi-square with Yates' correction $=10.32$ ). Males with intact wings experienced wounding at a greater rate than their numbers in the population would lead us to expect.

\section{Discussion}

Observation of an altered wing state upon recapture does not necessarily indicate a single pairing; there could have been two or more feedings with different females over the interval between captures. The observed low incidence of wounding on any given night is consistent with single-encounter woundings i.e. that males are effectively limited, by low numbers of sexually receptive females, to a single pairing over the time period of the study. It is also consistent, however, with multiple-encounter woundings to a few highly attractive males.

We began our study with more than $40 \%$ of the males in the population already wounded. If multiple woundings to a minority of more attractive males is the basis of a low proportion of wounded insects per night, then over the 7 nights which follow, most intercepted wing changes will occur to members of this, already large, minority. Hypothetically, by becoming wounded, males in this group have already demonstrated a superiority in forming pairs. Many of their intact-wing competitors have in theory been passed over and should continue to go unpaired during the ensuing study.

Our results do not support this hypothesis: the great majority of detected changes occurred to previousily intact rather than previously wounded males. We therefore consider it probable that each of our intercepted woundings represents contact with only one female.

On the basis of a significant difference in wounding we conclude that mating is more likely for a virgin than a wounded (hence putative non-virgin) male. This conciusion is qualified by evidence from laboratory studies (Dodson et al. 1983) that feeding can occur without successful mating. Three of 12 matings staged in the laboratory involved significant feeding on the wings by the female without culminating in the attachment of a spermatophore.

Dodson et al. also describe an instance in the laboratory where one male fed upon the wings of another, adopting the dorso-posterior mounting position of the female. The mere fact that a male is capable of feeding in this manner suggests that such behavior may occur in the field. It is not likely, however, to be a significant source of woundings in the wild since males are typically well separated; only rarely are they discovered within touching distance of each other; interaction at close range with another individual would provide abundant 
Table 2. Relative number of singer nights invested by intact and wounded males during the 7-day study. Numbers in parens are the number of intervening nights of calling and mating, undisturbed by our recapture attempts.

\section{NIGHT INTACT MALES SINGER NIGHTS WOUNDED MALES SINGER NIGHTS}

\begin{tabular}{lllll}
\hline 9 th & $41(2)$ & & $33(2)$ & \\
12 th & $21(1)$ & 82 & $29(1)$ & 66 \\
14 th & $19(2)$ & 21 & $33(2)$ & 29 \\
17 th & & 38 & & 66 \\
TOTALS & & 141 & & 161 \\
\hline
\end{tabular}


tactile cues as to sex, and males that permitted male feeding, in view of the apparent female preference for virgins, would be strongly selected against.

\section{Conclusion}

We conclude that virgin males of Cyphoderris strepitans enjoy greater mating success as a group than do putative non-virgins. Once a male has successfully mated, indeed once a male has suffered wing wounding even without sperm transfer, he is far less likely to secure a partner. This virgin advantage is in accordance with the theoretical prediction made at the outset. It is not necessarily the result of discrimination by females i.e. of female choice. Once-mated males might simply be forced by the need to replenish energy reserves to sing less as they forage for food, hence pairing less. It is also possible that the aggressive actions of virgin males displace non-virgins from habitat associated with the recruitment into the population of newly-molted, receptive females. Whatever the truth of such speculations, females typically pair with virgin mates and appear thereby to maximize the nutritive contribution from their male partner.

\section{Literature Cited}

Dodson, G. N., G. K. Morris and D. T. Gwynne. 1983. Mating behavior of the primitive orthopteran genus Cyphoderris (Haglidae). Pages 305-318. In D. T. Gwynne and G. K. Morcis, eds Orthopteran Mating Systems. Westview Press, Boulder.

Gwynne, D. T. 1983. Male nutritional investment and the evolution of sexual differences in Tettigoniidae and other Orthoptera. Pages 337-366. In D. T. Gwynne and G. K. Morris, eds. Orthopteran Mating Systems. Westview Press, Boulder.

Morris, G. K. 1979. Mating systems, paternal investment and aggressive behavior of acoustic Orthoptera. Fla Ent. 62:9-17. 